\title{
Intensification of Bioethanol Production by Simultaneous Saccharification and Fermentation (SSF) in an Oscillatory Baffled Reactor (OBR)
}

\author{
Joseph Ikwebe $^{1^{*}}$ and Adam P Harvey ${ }^{1}$ \\ ${ }^{I}$ Newcastle University, Newcastle upon Tyne, United Kingdom \\ *Corresponding author. Tel. +441912227169, Email: joseph.ikwebe@ncl.ac.uk
}

\begin{abstract}
Bioethanol is an alternative transport fuel produced mainly by the biochemical conversion of biomasses. This can be carried out efficiently and economically by simultaneous saccharification and fermentation (SSF): a process which integrates the enzymatic saccharification of the cellulose to glucose with the fermentative synthesis of ethanol. However, the SSF unit operation still contributes nearly $50 \%$ to the cost of ethanol production. For cellulosic ethanol to be cost competitive, there is the need to intensify the production process in smaller, more efficient and more economical bioreactors. In this work, SSF was performed in an intensified form of plug flow reactor, called the Oscillatory Baffled Reactor (OBR). The OBR is a continuous tubular reactor fitted with equally-spaced orifice plate baffles. An oscillatory component, provided by moving bellows in this design, is superimposed on the net flow through the reactor, generating short-lived vortices due to the interaction of the oscillating fluid with the baffles. This results in uniform mixing in each of the inter-baffle regions, with each behaving as a stirred tank reactor (STR), producing a plug flow residence time distribution (RTD) for the reactor as a whole, in which the mixing effects are largely decoupled from the mean flow (unlike conventional PFRs). The process was evaluated using 2.5\% SigmaCell cellulose, 40 FPU cellulase loading/g of cellulose and $10 \%$ cellobiase. Saccharomyces cerevisiae was employed as the fermenting organism at $38{ }^{\circ} \mathrm{C}$ and $\mathrm{pH}$ 4.8. In the first part of this work the use of the OBR resulted in a 7\% increase in glucose yield compared to a shake flask, after $48 \mathrm{~h}$ of saccharification and $8.0 \mathrm{~g} / \mathrm{L}$ ethanol in the OBR. This represented $89.8 \%$ of the theoretical yield, as compared to $7.7 \mathrm{~g} / \mathrm{L}$ in the shake flask representing $81.29 \%$, a difference of 9 percentage point. This increased glucose yield is attributable to better mixing in the OBR.
\end{abstract}

Keywords: Cellulose, Cellulase, Saccharification, Fermentation, OBR.

\section{Introduction}

The need to meet the ever-increasing demand for energy is probably one of the greatest challenges that society has to grapple with in this new millennium. Virtually every aspect of life on planet earth (heating, transportation, etc.,) requires energy input in one form or another. Hitherto, this energy need has been met principally by the use of fossil fuel resources [1]. However, it has been recognised that global crude oil reserves are finite, and their depletion is occurring much faster than previously predicted [2, 3]. In 2008, just at the onset of the global economic meltdown, crude oil price rose steeply up to a record USD 145. Also, the combustion of fossil fuels inevitably contributes significantly to elevated levels of greenhouse gases (GHG) and the attendant global warming [4]. Therefore, the need for more environmentally sustainable energy sources and the increased concern for the security of oil supply has put pressure on society to find renewable fuel alternatives [5].

Currently bioethanol is the dominant global renewable transport fuel and offers GHG savings of up to $80 \%$ over conventional fossil fuels [6]. It is produced primarily by the fermentative action of microorganisms (principally yeasts) on simple sugars [7]. Simultaneous saccharification and fermentation (SSF) can be used to convert the cellulosic part of biomass efficiently and commercially [8]. SSF combines the enzymatic saccharification of polymeric cellulose to simple monomeric forms such as glucose and its eventual fermentation by yeast to ethanol in the same vessel $[9,10]$. The enzymatic hydrolysis of cellulose is a complex reaction that depends on the synergistic action of several cellulases, which include endoglucanases that attack $\beta-1,4$ bonds randomly within the cellulase chains, $\beta-1,4$ 
cellobiohydrolases that remove successive cellobiose units from free chain ends, and $\beta$ glucosidase that break cellobiose up into glucose units[11, 12].

Most bioethanol companies that employ SSF technology use traditional stirred tank reactors in batch or continuous modes. Technology drawbacks associated with these conventional bioreactors are well-documented. These include inadequate mixing resulting in inconsistent product qualities. Ni et al.[13] have demonstrated that consistent product quality results from and is inherently associated with consistent fluid mechanics in OBRs. Also, Mackley and Ni [14] have shown that product uniformity is determined by efficient fluid mixing which also is dependent on efficient heat and mass transfer. Other drawbacks include huge inventories[15], the prohibitive costs of large reactors, and associated downtimes which impact negatively on profitability. In spite of the advantages the SSF brings to bioethanol fermentation, its unit operation still contributes nearly $50 \%$ to the cost of ethanol production [16]. For cellulosic ethanol to be cost competitive, there is the need to intensify the production process in smaller, more efficient and more economical bioreactor. The oscillatory baffled reactor (OBR) is one such bioreactor.

\subsection{The Oscillatory Baffled Reactor}

The OBR is a continuous tubular reactor fitted with equally-spaced orifice plate baffles[15]. An oscillatory component, provided by moving bellows in this design, is superimposed on the net flow through the reactor, generating short-lived vortices due to the interaction of the oscillating fluid with the baffles. This results in uniform mixing in each of the inter-baffle regions, with each behaving as a stirred tank reactor (STR)[13], producing a plug flow residence time distribution (RTD), in which the mixing effects are largely decoupled from the mean flow (unlike conventional PFRs)[17]. It has been demonstrated by Mackley and Ni[18], $\mathrm{Ni}$ et al.[19], and $\mathrm{Ni}$ et al.[20] that excellent mixing conditions in a tubular reactor can be achieved when vigorous eddies are generated between periodically-spaced baffles as a result of the introduction of oscillations. A typical OBR configuration is revealed in Figures 1 while Figure 2 shows a typical flow pattern in a cell.

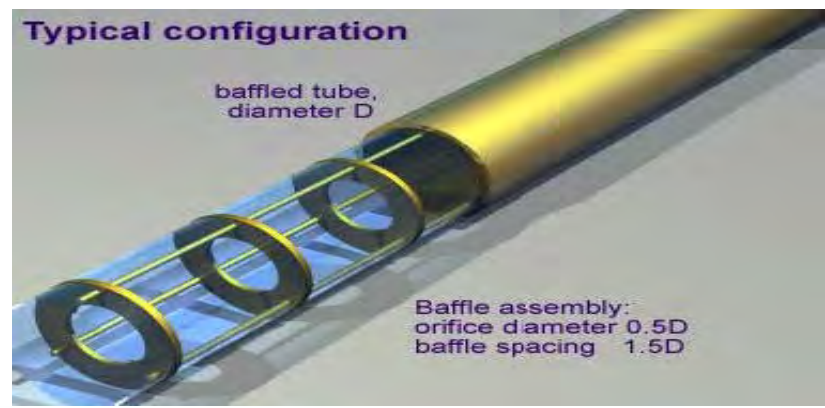

Figure 1. Layout of the OBR[21]

The intensity of the mixing under oscillatory flow is characterised by the oscillatory Reynolds number, $\operatorname{Re}_{0}$ defined as:

Oscillatory Reynolds number: $\operatorname{Re}_{o}=\frac{\rho 2 \pi f x_{o} d}{\mu}$

where $d$ is the internal tube diameter (m), $f$ is the fluid oscillation frequency $\left(\mathrm{s}^{-1}\right), x_{o}$ is the fluid oscillation amplitude (m) measured from centre-to-peak, and $\mu$ and $\rho$ are the fluid viscosity $\left(\mathrm{kg} \mathrm{m}^{-1} \mathrm{~s}^{-1}\right)$ and density $\left(\mathrm{kg} \mathrm{m}^{-3}\right)$, respectively. 


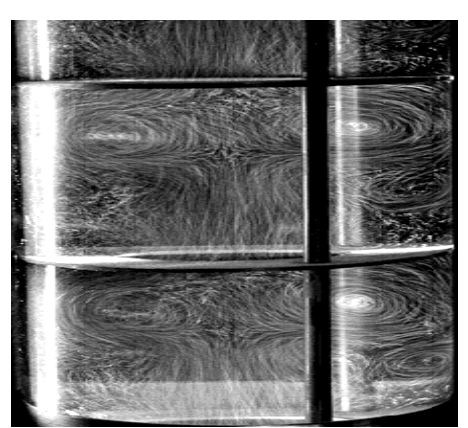

Figure 2 Flow patterns showing vortices and mixing in individual OBR cells[13].

The OBR has already been touted [22] to have the potential to lower costs by $50 \%$ and process times by $90 \%$ in the manufacture of commodities including chemicals, drugs and biofuels. Reis et al.[23] have demonstrated the potential of the OBR for bioreactions by achieving a $50 \%$ decrease in process time of the production of $\gamma$-decalactone compared to the stirred tank bioreactor and shake flasks. Gaidhani et al.[24] demonstrated the adaptability of the OBR in the cultivation of microorganisms for the synthesis of pullulan when then they also achieved a $50 \%$ reduction in process time in comparison with a parallel STR. They argued that the process time reduction is as a result of a more uniform mixing environment for cell growth and excellent mass transfer characteristics.

In this study the OBR is used in the simultaneous saccharification and fermentation of cellulose to produce ethanol.

\section{Methodology}

\subsection{Enzymatic saccharification}

The enzymatic saccharification was carried out using SigmaCell cellulose, Type 50 from Sigma-Aldrich following the NREL LAP, "Enzymatic saccharification of lignocellulosic biomass"[25]. This method measures the rate of conversion of cellulose by the synergistic action of cellulases. $250 \mathrm{~mL}$ conical flasks were used in the shake flask experiments and a total saccharification volume of $50 \mathrm{~mL}$ containing $2.5 \% \mathrm{w} / \mathrm{v}$ cellulose loadings. Cellulolytic enzymes, cellulose and $\beta$-glucosidase (both kind gifts from Novozymes, Denmark) with activity of 100 Filter Paper Unit (FPU)/g and 250 Cellobiose Units (CBU)/g respectively were employed. 10, 20, 4070 and $100 \mathrm{FPU} / \mathrm{g}$ cellulose loadings each containing $10 \% \beta$ glucosidase were evaluated. The shake flasks were incubated at $50{ }^{\circ} \mathrm{C}$, the optimum temperature of the enzymes, and a pH of 4.8 and 200 RPM agitation. The saccharification was also carried out at $38{ }^{\circ} \mathrm{C}$ the optimum fermentation temperature of the yeast ascertain the glucose available to the yeast during the fermentation. However, the saccharification medium contained $1 \%$ yeast extract and $2 \%$ peptone on this occasion. The experiments were run for $168 \mathrm{~h}$ and replicate samples collected periodically over time.

In the OBR saccharification 2.5, 5 and $10 \% \mathrm{w} / \mathrm{v}$ cellulose loadings were also evaluated but with $40 \mathrm{FPU} / \mathrm{g}$ and $10 \% \beta$-glucosidase at the same temperatures and $\mathrm{pH}$ as the shake flasks. The oscillation frequency was $3 \mathrm{~Hz}$, centre-to-peak amplitude $0.03 \mathrm{~m}$ and a Reynolds number $\mathrm{Re}_{\mathrm{o}}$ of 1760. The OBR experimental set up is as shown in Figure 3 below. 


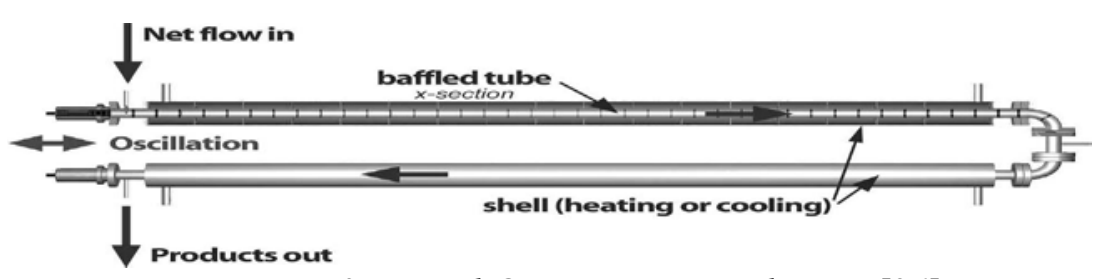

Figure 3 Typical OBR experimental set up[26].

\subsection{Simultaneous Saccharification and Fermentation (SSF)}

The SSF experiments were performed using 2.5\% w/v cellulose and $40 \mathrm{FPU} / \mathrm{g}$ in both the shake flasks and OBR. YP medium (10 g/L yeast extract and $20 \mathrm{~g} / \mathrm{L}$ peptone) was used. The pHs was 4.8 and temperature $38{ }^{\circ} \mathrm{C}$ in both systems and were also all equipped with carbon dioxide traps to simulate anaerobic conditions. The same agitation conditions were maintained in both systems as in the saccharification experiments. The inocula were prepared from a pure culture of baker's yeast Saccharomyces cerevisiae and cultivated on YPD medium (10 g/L yeast extract, $20 \mathrm{~g} / \mathrm{L}$ peptone and $50 \mathrm{~g} / \mathrm{L}$ glucose-filter-sterilised). The NREL LAP "SSF Experimental Protocols- Lignocellulosic Biomass Hydrolysis and Fermentation"[27] was followed completely in the SSF experiments in both cases. A 10\% inoculum was used to initiate the SSF and replicate samples collected periodically.

\subsection{Analyses}

In both the saccharification and fermentation experiments, samples were collected periodically, spun in a microcentrifuge (Sanyo) at 13000 RPM. The supernatants were analysed for glucose using the dinitrosalicylic acid (DNS) method [28] and absorbance measured with a Jenway 6105 UV/VIS spectrophotometer. Ethanol was analysed using gas chromatograph (Hewlett-Packard 5890 Series II) with column packed with porapak 50/80 mesh as instructed in the NREL LAP[29].

\section{Results}

Enzymatic saccharification experiments in both the shake flasks and OBR were carried out under identical conditions and the degree of cellulose conversion- representing the concentration of glucose produced were monitored (Figure 4). $78.3 \%$ saccharification of cellulose was observed in the shake flasks at $100 \mathrm{FPU} / \mathrm{g}$ cellulose and $71 \%$ at $40 \mathrm{FPU} / \mathrm{g}$ cellulose after $144 \mathrm{~h}$ of hydrolysis at $50{ }^{\circ} \mathrm{C}$. Hence $40 \mathrm{FPU} / \mathrm{g}$ cellulose was used in the OBR experiment which represented a trade-off between cellulase efficiency and enzyme cost. 78\% saccharification was recorded in the OBR at the end of $144 \mathrm{~h}$ of hydrolysis at $50{ }^{\circ} \mathrm{C}$.

The 5 and 10\% cellulose loadings exhibited various degrees of reduced saccharification (data not shown). Figure 5 represents the results of the saccharification experiment at $38{ }^{\circ} \mathrm{C}$, the fermentation temperature of the yeast. The OBR also showed at least 10 percentage point more conversion than the shake flask at $40 \mathrm{FPU} / \mathrm{g}$ of cellulose.

Samples were taken periodically during the SSF and analysed for glucose and ethanol as described above. Figure 6 shows the time-course of the ethanol production and glucose production/utilisation during the SSF of $2.5 \%$ cellulose at $40 \mathrm{FPU} / \mathrm{g}$ cellulose in both shake flasks and OBR. Whereas ethanol fermentation peaked at $45 \mathrm{~h}$ in the OBR it was at $70 \mathrm{~h}$ in the shake flasks. Glucose production peaked at $20 \mathrm{~h}$ and then began to drop steeply until it was almost completely used up by the yeast by the end of the fermentation. Ethanol yield 


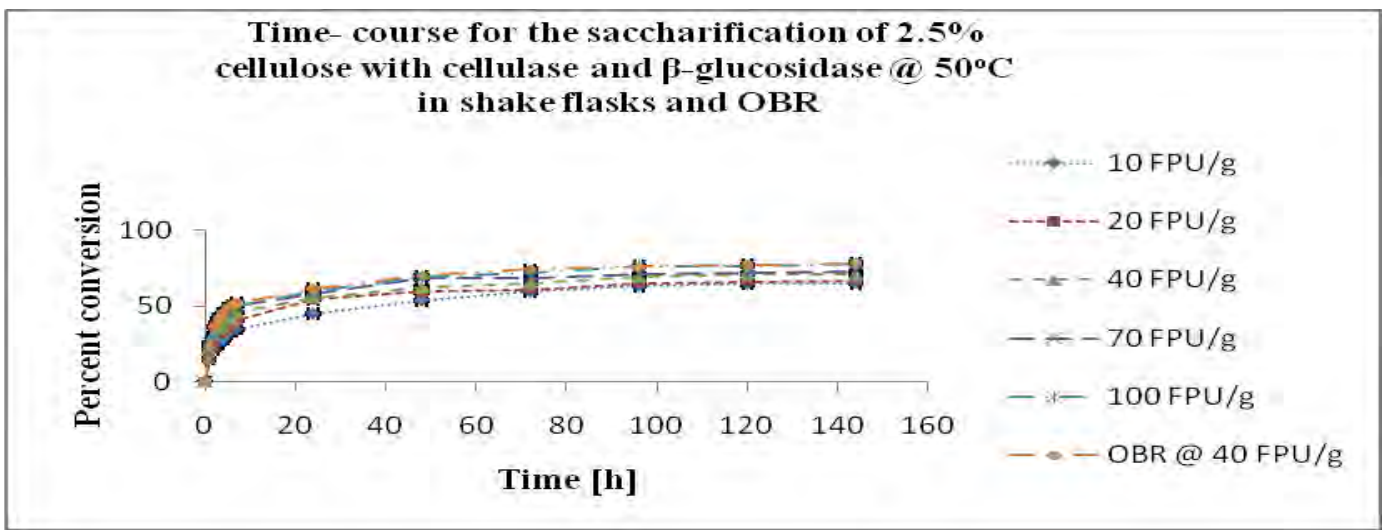

Figure 4. Time-course for the saccharification of 2.5\% cellulose with cellulase and $\beta$-glucosidase @ $50^{\circ} \mathrm{C}$ in shake flasks and $\mathrm{OBR}$.

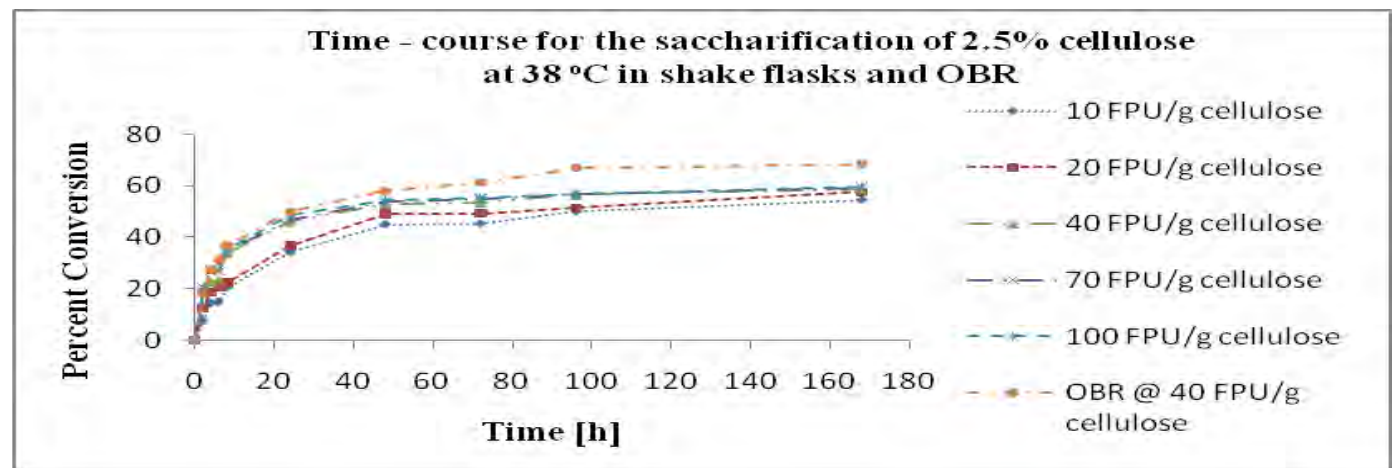

Figure 5. Time-course for the saccharification of $2.5 \%$ cellulose at $38{ }^{\circ} \mathrm{C}$ in shake flasks and $O B R$.

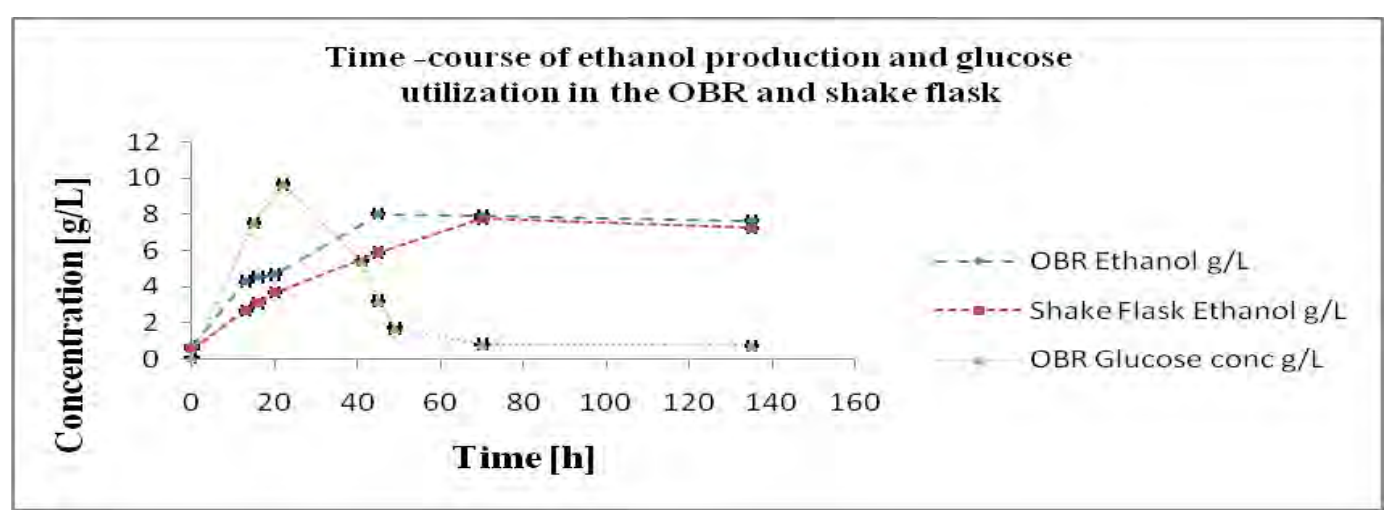

Figure 6. Time-course of ethanol production and glucose utilization in the OBR and shake flask.

increased steadily in both systems but in the OBR it peaked at $8 \mathrm{~g} / \mathrm{L}(89.8 \%$ of theoretical yield) after $45 \mathrm{~h}$ fermentation and then began to decline. However, in the shake flasks it peaked at $7.7 \mathrm{~g} / \mathrm{L}$ (81.29\% theoretical yield) after $70 \mathrm{~h}$ fermentation and began to decline.

\section{Discussion and conclusion}

The saccharification experiments exhibited classical cellulosic hydrolysis characteristics: an initial rapid saccharification phase within the first $24 \mathrm{~h}$ and a much slower later phase (Figure 4 and 5) [30, 31]. The initial rapid phase may be as a result of the easily digestible amorphous part of the cellulose which is more readily available to the cellulases [32]. The later slower phase may be as a result of the crystalline, more recalcitrant part of the cellulose which limits accessibility to the enzymes [9]. The OBR and shake flask experiments exhibited a similar 
SSF pattern. 2.5\% cellulose loading was chosen for the SSF as it registered the highest percent saccharification as compared to the 5 and 10\% (data not shown). The probable reason may be mixing problems and substrate inhibition as the substrate concentration increases [30, 31]. However using the OBR resulted in $7 \%$ more saccharification over the shake flask at the end of $168 \mathrm{~h}$ of saccharification is possibly as a result of a better mixed hydrolysis environment.

During the first phase of the SSF glucose accumulated within the first $22 \mathrm{~h}$ of the process (Figure 6) indicating the yeast cells could not cope with the rate of glucose generation by the enzymes[9]. But as cell mass continued to increase there was also a corresponding uptake of glucose which resulted in a steady rise in ethanol concentration up to the $45 \mathrm{~h}$ in the OBR and $70 \mathrm{~h}$ in the shake flasks. However, as the generated glucose was used up, the cells began to use ethanol as a carbon source corresponding to the gradual decline in the concentration of ethanol. This probably happened during sampling as air entered the systems to enable a switch of carbon source to ethanol by the cells. A similar phenomenon was also observed by Philippidis and Smith[9].

Although the concentration of ethanol from the two systems were similar (8 g/L OBR vs. 7.7 $\mathrm{g} / \mathrm{L}$ shake flask), the OBR attained this concentration $25 \mathrm{~h}$ earlier than the shake flask. This would lead to a $\sim 30 \%$ higher productivity for the same size of reactor. Furthermore it should be noted that OBRs are scaleable: what can be achieved at this scale, can probably also be achieved at industrial scale [33]. The same cannot be said of conventional stirred vessels, in which reaction times increase with scale, as good mixing becomes increasingly difficult to achieve. This also is possibly due to a better mixed SSF environment in the OBR which promoted better mass transfer characteristics. It agrees with the findings of Gaidhani et al.[34] who showed that it took $52 \mathrm{~h}$ for the cells to reach the stationary phase in the OBR compared to128 $\mathrm{h}$ in the STR.

These results provide a platform for further investigation into the applicability of the OBR in continuous SSF.

\section{Acknowledgement}

This study was funded by the Petroleum Technology Development Fund (PTDF) and the Nigeria government.

\section{References}

[1]. B. Palmarola-Adrados, T. Juhász, M. Galbe, and G. Zacchi, Hydrolysis of nonstarch carbohydrates of wheat-starch effluent for ethanol production. Biotechnology Progress. 20(2), 2004, p. 474-479.

[2]. F.W. Bai, W.A. Anderson, and M. Moo-Young, Ethanol fermentation technologies from sugar and starch feedstocks. Biotechnology Advances. 26(1), 2008, p. 89-105.

[3]. R. Möller (2006) Cell Wall Saccharification: Outputs from the EPOBIO projects. Cell Wall Saccharification Volume, 1-69

[4]. T.M.L. Wigley, The climate change commitment. Science. 307(5716), 2005, p. 17661769.

[5]. B. Hahn-Hägerdal, M. Galbe, M.F. Gorwa-Grauslund, G. Lidén, and G. Zacchi, Bioethanol- the fuel of tomorrow from the residues of today. TRENDS in Biotechnology. 24(12), 2006, p. 8. 
[6]. P. Billins, J. Woods, and R. Tipper, Developing carbon and greenhouse gas assurance for bioethanol production in the UK. 2005, Home Grown Cereals Authority (HGCA). p. $1-64$.

[7]. A. Demirbas, Bioethanol from cellulosic materials: A renewable motor fuel from biomass. Energy Sources. 27(4), 2005, p. 327-337.

[8]. J.D. Wright, C.E. Wyman, and K. Grohmann, Simultaneous Saccharification and Fermentation of Lignocellulose: Process Evaluation. Applied Biochemistry and Biotechnology. 18, 1988, p. 75-90.

[9]. G.P. Philippidis and T.K. Smith, Limiting factors in the simultaneous saccharification and fermentation process for the conversion of cellulosic biomass to fuel ethanol. Applied Biochemistry and Biotechnology. 51/52, 1995.

[10]. M. Ballesteros, J.M. Olivia, M.J. Negro, P. Manzanares, and I. Ballesteros, Ethanol from lignocellulosic materials by a simultaneous saccharification and fermentation process (SFS) with Kluyveromyces marxianus CECT 10875.Process Biochemistry. 39, 2004, p. 6.

[11]. Z. Xiao, R. Storms, and A. Tsang, Microplate-based filter paper assay to measure total cellulase activity. Biotechnology and Bioengineering. 88(7), 2004, p. 832-837.

[12]. C. Breuil and J.N. Saddler, Comparison of the 3,5-dinitrosalicylic acid and NelsonSomogyi methods of assaying fo reducing sugars and de termining cellulase activity. Enzyme and Microbial Technology. 7, 1985, p. 327-332.

[13]. X. Ni, M.R. Mackley, A.P. Harvey, P. Stonestreet, M.H.I. Baird, and N.V. Rama Rao, Mixing through oscillations and pulsations -A guide to achieving process enhancements in the chemical and process industries. Chemical Engineering Research and Design. 81(3), 2003, p. 373-383.

[14]. M.R. Mackley and X. Ni, Experimental fluid dispersion measurements in periodic baffled tube arrays. Chemical Engineering Science. 48(18), 1993, p. 3293-3305.

[15]. A. Harvey and P. Stonestreet, Oscillatory flow: A technology ready to deliver. Chemical Engineer. (720), 2001, p. 41.

[16]. NREL, Research Advances- Cellulosic Ethanol. National Renewable Energy Laboratory. A National Laboratory of the U.S. Department of Energy, Office of Energy Efficiency \& Renewable Energy. 2008.

[17]. A.P. Harvey, M.R. Mackley, and T. Seliger, Process intensification of biodiesel production using a continuous oscillatory flow reactor. Journal of Chemical Technology and Biotechnology. 78, 2003, p. 338-341.

[18]. M.R. Mackley and X. Ni, Mixing and dispersion in a baffled tube for steady laminar and pulsatile flow. Chemical Engineering Science. 46(12), 1991, p. 3139-3151.

[19]. X. Ni, J.A. Cosgrove, A.D. Arnott, C.A. Greated, and R.H. Cumming, On the measurement of strain rate in an os cillatory baffled column using particle image velocimetry. Chemical Engineering Science. 55(16), 2000, p. 3195-3208.

[20]. X. Ni, H. Jian, and A.W. Fitch, Computational fluid dynamic modelling of flow patterns in an os cillatory baffled column. Chemical Engineering Science. 57(14), 2002, p. 2849-2862.

[21]. X.-W. Ni, A. Fitch, and P. Webster (2003) From a Maximum to Most Efficient Production Using a C ontinuous Oscillatory Baffled Reactor. Centre for Oscillatory 
Baffled Reactor Applications (COBRA), Chemical Engineering, School of Engineering and Physical Sciences, Heriot-Watt University, Edinburgh, EH14 4AS Volume,

[22]. The Scotsman, Scottish Business Briefing: Tuesday, 2ndO ctober, 2007. Scotsman.com http://business.scotsman.com/scottishbusinessbriefing/Scottish-BusinessBriefing--Tuesday.3465134.jp. 2007.

[23]. N. Reis, C.N. Goncalves, M. Aguedo, N. Gomes, J.A. Teixeira, and A.A. Vicente, Application of a nov el oscillatory flow micro-bioreactor to the production of $\gamma$ decalactone in a two immiscible liquid phase medium. Biotechnology Letters. 28(7), 2006, p. 485-490.

[24]. H.K. Gaidhani, B. McNeil, and X.W. Ni, Production of pullulan using an oscillatory baffled bioreactor. Journal of Chemical Technology and Biotechnology. 78(2-3), 2003, p. 260-264.

[25]. N. Selig, N. Weiss, and Y. Ji, Enzymatic Sacharification of Lignocellulosic Biomass. Laboratory Analytical Procedure (LAP) National Renewable Energy Laboratory (NREL) 2008, p. 1-5.

[26]. A. Harvey and P. Stonestreet, A mixing-based design methodology for continuous oscillatory flow reactors. Trans IChemE, Part A, Chemical Engineering Research and Design. 80, 2002, p. 31-44.

[27]. N. Dowe and J. McMillan, SSF Experimental Protocols- Lignocellulosic Biomass Hydrolysis and $F$ ermentation. National Renewable Energy Laboratory Analytical Procedure. LAP, 2001, p. 1-16.

[28]. G.L. Miller, Use of Dinitrosalicylic Acid Reagent for Determination of Reducing Sugar. Analytical Chemistry. 31(3), 1959, p. 426-428.

[29]. D.W. Templeton, Determination of Ethanol Concentration in Biomass to Ethanol Fermentation Supernatants by Gas Chromatography. National Renewable Energy Laboratory Analytical Procedure. LAP-011, 1994, p. 1-10.

[30]. J. Szczodrak, The enzymatic hydrolysis and fermentation of pretreated wheat straw to ethanol. Biotechnology and Bioengineering. 32, 1988, p. 771-776.

[31]. S. Hari Krishna, K. Prasanthi, G.V. Chowdary, and C. Ayyanna, Simultaneous saccharification and fermentation of pretreated sugar cane leaves to ethanol. Process Biochemistry. 33(8), 1998, p. 825-830.

[32]. M.R. Ladisch, C.M. Ladisch, and G.T. Tsao, Cellulose to sugars: New path gives quantitative yield. Science. 201(4357), 1978, p. 743-745.

[33]. K.B. Smith and M.R. Mackley, An experimental investigation into the scale-up of oscillatory flow mixing in baffled tubes. Chemical Engineering Research and Design. 84(11 A), 2006, p. 1001-1011.

[34]. H.K. Gaidhani, B. McNeil, and X. Ni, Fermentation of pullulan using an oscillatory baffled fermenter. Chemical Engineering Research and Design. 83(6 A), 2005, p. 640645. 